\title{
New Cyclic Technology for Thermal Treatment of Complicated Formations
}

\author{
* Kudinor V. T., ** Kolbikov V. S., * Datsik M. L, \\ * Zubov N. M., **. Volkova V. V. \\ * Udmurtneft, Russia \\ ** Kuban Oil Research Co.
}

Copyright 1996, Steering Committes of the Europesn lOR - Symposium.

This paper was presented at the 8th. European tOR - Symposium in Vienna, Aurtria. May 16 - 17, 1995

This paper was selected for presentetion by the Steering Committee, following roview of information contained in en abstract submitted by the author(s). The paper, as presented has not been reviowed by the Steering Committes.

\section{ABSTRACT}

The idea of artificial change of formation temperature to increase oil production has a long listory. since the beginning of the 20th century.

Different methods and technologies to heat heavy oil has being created and implemented in deferent scales.

This methods compose of three main trends:

- producing wells bottom-hole thermal treatment;

- formation treatment by heat carriers injection and;

- in-situ combustion process.

The first two methods are most widely developed and provide involvement into commercial production formations with wide range of viscosities with safe and environmentally reliable operation procedures.

The paper describes the perfection of technological processes of heat carrier injection into the reservoir. ained at solution of the most substantial development problems concerning "difficult-torecover" reserves.

Mentioned below are the most essential problems. solved to a cernain extent:

- effeclive use of heat-generating means, existed in the given project;

- saving of generating agents to be injected into a reservoir;

- higher process heat efficiency and reservoir sweep which results in remarkable increase of recoverable oil reserves giving the opportunity to put into production the heavy oil reservoirs with complicated geological properties.
New heat-treatment technologies have been created and applied by the Russian Joint-Stock Company "UdmurtNeft" together with the Kuban Oil Research and Technological Company (KNTK- Neft) and the RosNIPItermneft Institute. All the technologies considered below have been patented in Russia. World experience as well as practice of Udmurt oil fields development where the new technologies were being created have been analyzed.

\section{INTRODUCTION}

Three new technologies, [1,2 and 3] are to be considered in the paper. For practical utilization these technologies were named as:

- Pulse-Dozing Heat Treatment of the formation (PDHT);

- Pulse-Dozing Heat Treatment of the formation with Pauses (PDHT(P)) and

- Thermal Cyclic Treatment of the Bed (TCBT).

The paper reveals the basic features of physical and hydrothermodynamic al essence of new technologies, oil-recovery mechanism. peculiarities of bed stimulation technology choice under various geological conditions. Geological and physical criteria for reservoirs option where application of new technologies will make it possible to gain high technological and economical efficiency are described

The results of field application of new technologies on'high viscosity oil deposit in the Gremikhinskoye heavy oil field. Udmurtia are also considered. 


\section{THE NATURE . OF NEW FORMATION TREATMENT TECHNOLOGIES}

As to the peculiarities of application of PDHT, PDHT(P) and CBHT they are quite simple and do not need additional capital investments. On the contrary decrease them for $25 \%$. The nature of thermodynamic processes of the oil stimulation principally differs from all known themal EOR methods.

\section{Pulse-dosing heat treatment technology (PDHT)}

The main idea of PDHT technology is a combination of cyclic (altemating) heat-carrier and cold water injection into the reservoir in strictly rated volumes to ensure heat front distribution in the formation. Such approach was used earlier but in arbitrary proportions. In these technologies the grounding of displacement agent injection modes for concrete geological conditions was not taken into consideration. The notion of effective formation temperature (ERT) described as maximum reservoir temperature provided the best flow properties of heavy oil and determined from "temperature-oil viscosity" curve, was used for the first time for development of PDHT technology.

Thus every individual. oil-pool has its own effective formation temperature (ERT) which should not be exceeded, as it is not protitable. ERT is taken as a basis for determination the ratio of the required quantity of heat-carrier injection $\mathrm{Q}(\mathrm{HC})$ and that of cold water $\mathrm{Q}(\mathrm{CW})$ which is a function of geological characteristics of heat-treated formation. the system of its drilling in. thermophysical properties of rocks and saturating fluids. the thermal characteristics of the agent injected, the rate of injection and ERT.

The calculations of the PDHT mode comprise:

- determination of ERT from the "viscositytemperature" curve;

- determination of the total volume of heat-carrier Q(T), sufficient for heating the reservoir to the effective temperature in the given pattern of treatment;

- determination of heal-carrier parameters in the inlet to the reservoir, considering the type of utilized heat generating facilities and equipment of the injection wells;

- determination of ratio between total injection volume of heat-carrier and cold water $\mathrm{Q}(\mathrm{HC}) / \mathrm{Q}(\mathrm{CW})$;

- determination of the total volumes of heat-carrier $\mathrm{Q}(\mathrm{HC})$ and cold water $\mathrm{Q}(\mathrm{CW})$ at the stage of PDHT, taking into account that $\mathrm{Q}(\mathrm{HC})+\mathrm{Q}(\mathrm{CW})=2,5 \mathrm{PV}$ (where (PV) is a pore volume of pattern treated) and choice on this ground of the ratio between heatcarrier injection and cold water pulses $\mathrm{P}(\mathrm{HC}) / \mathrm{P}(\mathrm{CW})$ in cyclic process:

- setting the value of one heat-carrier's pulse $P(H C)$ of that of cold water;

- determination of the number of PDHT cycles (n) during the entire period of this technology application:

$$
n=\frac{2,5 \mathrm{PV}}{P(\mathrm{HC})+P(C W)}
$$

- determination of the cold water quantity required to drive the thermal slug at the sweep-out stage after PDHT process.

PDHT is a comparatively effective, power-andresource saving and environmentally reliable heavy oil pool stimulation technology.

Energy saving is attained in the technology mostly though limitation of heat amount introduced into reservoir in accordance with its heating up to the effective temperature apart from that. Mathematical simulation of PDHT process shows heat Rosses decline to the surrounding rocks and a higher factor of heat consumption in comparison with the traditional steam and hot water stimulation technologies.

Oil recovery enhancement during PDHT is provided mainly by speeding-up the reservoir coverage by thermal stimulation due to steady raising of the number of steam injection wells. Cyclic heat injection provides to use effectively the heat generating facility for more injectors because during injection of could water this facility is used for heat injection in another pans of reservoir. With equal amount of heat carrier delivered to the formation using conventional steam and hot water injection, the technology of PDHT guarantees much higher thermal utilization factor due to decrease of heat-losses in the surrounding rocks and higher oil recovery coefficient.

In the above technologies the main difference in thermal field formation dynamics and reservoir medium temperature conditions are observed [Fig.1].

In case of hot water injection a high temperature area $\left(100-200^{\circ} \mathrm{C}\right)$ is continuos, expanding up to the radius equal to almost half the radius of pattern stimulated. It is evident that in this case a long time (about 10 years), active unproductive heat exchange occurs between high and low temperature environment. In case of PDHT more condensed high- 
temperature area with an active double sighting pulse heat exchange is being formed. The above mentioned effects are most characteristic for the formations non-uniform in porosity and permeability. especially for the pours-fractured type formations. In this case oil recovery from low permeable blocks (matrices) due to termo-capillary processes is very important.

Numerical simulation of themal mass exchange in the formation considering themal fluctuations allows to give a quantitative evaluation of efficiency in the oil recovery increase that to the share of lowpermeable blocks. Thus, for oil with initial viscosity of $200 \mathrm{mPa} \cdot \mathrm{s}$ and formation temperature of $20^{\circ} \mathrm{C}$ a single cycle of temperature change inherent in steam stimulation and hot water stimulation methods makes oil recovery from blocks equal to $23 \%$.

With Multiple repetition of temperature change cycles, which is inherent to PDHT mode, the above value of oil recovery becomes $46 \%$ - twice higher.

Thus the major distinctive features of PDHT technology as compared to continuos heat carrier injection followed by cold water (steam stimulation, hot water stimulation etc.) are as follows:

- formation coverage by thermal stimulation is accelerated through cyclic liberation of energy when heat-carrier is injected into the wells;

- conditions for effective oil-pool development are created using limited quantity of heat generating facilities;

- thermal efficiency of the process rises due to a more rational mode of heat injection and heat losses reduction to the environmental rocks:

- ultimate oil recovery improves. Such an effect is most characteristic for non-uniform formations, particularly for porous-fractured reservoirs. It is for these reservoirs that the mechanism of oil recovery from low-permeable blocks is of great importance due to the activation of thermocapillary processes.

In the PDHT process the conventional steaminjection wells, subsurface, well head and surface facilities and equipment are used.

\section{Pulse-dosing pauses heating technology (PDHT(P))}

This technology is the modification of pulse-dosing heat treatment (PDHT) and differs from the latter one by the cold water injection in passes $P(C W)$.

The entire cycle of stimulation comprises the stages of heat-carrier pulse injection $\mathrm{P}(\mathrm{HC})$ and that of cold water. which are not entered short-term shut-downs (pauses) of the injection wells. The number of pauses in a pulse $P(C W)$ and their duration are described in [2].

It has been determined that duration of one pause for the given formation should not be lees than time necessary for pressure build-up after change of operation modes or well shut-down (usually 3-5 days). This time is sufficient the effect become evident as to oil displacement from low permeable matrix to high permeable porous or porous-fractured part of reservoir.

Total duration of shut downs in the cyclic changes within $10-15 \%$ of $P(C W)$. Such limitation is selected because with high effective temperature total heat losses increase to the environmental rocks is observed. Heat carrier and cold water injection modes were performed according to [1] and [2].

Possessing all the merits of PDHT, the PDHT(P) technology ensures additional increment of oil recovery factor by not less than $3 \%$.

\section{Cyclic heat treatment of formation (CBHT)}

The essence of cyclic heat treatment technology consists in arranging an integral thermal drive process through the system of injection and production wells. The major advantage of CBHT is faster involvement of pay zones to the heat treatment, increase in capacity of production wells system. and as a consequence, higher sweep of reservoirs with displacement and increased ultimate oil recovery.

As applied to wells spacing. e.g. converted 7 spot spacing, in order to carry out one complete CBHT cycle, the following technique is used [Fig.2]:

- the injection of heat-carrier into the bed is realized simultaneously through the central injection well (in PDHT(P) mode) and three production wells located at every other vertex of a hexagon. Oil production is made through the other three production wells:

- the groups of production wells change their functions: the wells which were used for injection of heat-carrier are converted to production status and vice versa; the central well operating mode does not alter,

- all the production wells are changed over to the withdrawal status and the heat carrier injection in PDHT(P) mode is performed through the central well.

From 3 to 5 complete CBHT cycles are provided with further convert to cold water drive through the central injection well and transition of all production wells to the withdrawal mode. 
In order to ensure the maximum coverage of pattem area with themal and hydrodynamic treatment to increase the final oil recovery it is essential to substantiate in CBHT technology such parameters as:

- amount of heat-carrier required for the particular pattem treatment:

- distribution of the required heat-carrier between the central injection well and the production wells of the given pattem;

- rates of heat-carrier injection into the central and peripheral production wells:

- duration of stages in CBHT cycles;

- number of cycles in CBHT mode.

\section{SCREENING CRITERIA TO CHOICE FORMATIONS FOR TREATMENTS}

First of all, the PDHT, PDHT(P) and CBHT technologies meet commonly used geological and physical criteria for application of heat-carrier injection. In situ activization of thermocapillary and hydrodynamic processes associated with realization of the above technologies significantly increases their efficiency in heterogeneous porous media. The heterogeneity can be displayed either by the multizone type of reservoir or by its zone variability.

For successful application of described technologies the following geological and physical criteria should be used:

- oil-pools with practically any type of deposition conditions;

- single and multiple zones but hydrodynamically integral heterogeneous systems from their porosity and permeability point of view, with net pay thickness of 6,0 meters and more;

- formations with carboniferous and terrigenous, porous or porous-and-fractured reservoir;

- wide range of viscosity - from medium to very heavy crude with high content of resins and wax (especially when the pour point is close to the reservoir temperature). deposits with low formation temperatures;

- criteria for depths and reservoir pressure are limited by existed field facilities (type of steam generation and downhill thermal insulation systems);

- oil saturation and oil reserves density (value of reserves per a specific unit of formation) are limited by economic factors, when the used systems and technologies of development are profitable.

\section{FIELD APPLICATION}

PDHT, PDHT(P) and CBHT technologies have been tested and applied in wide scale in the oil fields of Udmurtia Republic. Russia.
Udmurtia Republic is young oil producing region. By the present 65 oil fields have been disçovered in the Republic with the total oil reserves of 2,0 billion tons.

Main oil reserves are situated in the deposits of Carboniferous period at the depth of $900-1500$ meters. Oils are heavy, viscous with high content of parafin and resins. Formations under development are mainly multibed, highly heterogeneous as to permeability, porosity and oil saturation. Productive formations are porous and porous-fractured, carbonate and terrigeneous type. According to oil reserves and the degree of their withdrawal Udmurtiya can be attributed to perspective oil producing regions of Russian Federation.

With due regard to geological characteristics thermal EOR methods have many advantages among other EOR technologies, as providing a substantial improve of flow features and oil recovery enhancement and gaining high profitability.

The main target of new technologies commercial development is A4 formation of Bashkir stage. middle Carboniferous period of the Gremikhinskoye oil field. The deposit is represented by anticline with gentle wings, crest-type, massive beds with aquifer. The log service shows non uniform interceding of porous, porous-and-fractured, and tight beds and streaks of limestone: gross thickness is 85 meters, average oil saturated thickness 24,4 meters, the average porosity is 0,19 , permeability $0,105 \mathrm{D}$ with fluctuations up to 2,5D. Oil saturation - 0.84 ; depth of deposition -1200 meters.

Oil is heavy (905kg/cub.m). viscous $(90-180 \mathrm{mPa} \cdot \mathrm{s}$ at reservoir temperature) with low content of dissolved gas (6,0 cub.m/ton). The oil-pool is characterized by elastic water-drive with initial reservoir pressure $12,5 \mathrm{MPa}$ and reservoir temperature $28^{\circ} \mathrm{C}$.

The commercial development of the deposit was initiated in 1981 with application of converted triangular patterns with 173 meters spacing between the wells. All the wells were put into operation by natural drive and after partial utilization of the natural reservoir energy, up to the current formation pressure - 7-8 $\mathrm{MPa}, 7$-spot pattern elements were formed. The injection of heat-carrier into the bed was started in 1983 .

During the 12-year period of the oil-pool commercial development, the following technologies have been applied: hot water injection of high parameters $\left(+260^{\circ} \mathrm{C}\right)$ with formation of preset thermal slugs (HWT), pulse-dosing heat treatment (PDHT) and its 
modifications PDHT(P) and CBHT. All the technologies featured case of practical technique using standard injection and production facility.

Following are the major parameters for injection of agents:

a) Parameters of conventional heat carrier-injection technology:

- injection rate - 160 tons per day, heal-carrier temperature at the well head $260^{\circ} \mathrm{C}$ and $180-200^{\circ} \mathrm{C}$ at the well bottom;

- injection pressure - 4,5-6 $\mathrm{MPa}$ (heat-carrier in a liquid phase-hot water);

b) Parameters of PDHT:

- pulse duration: $P(H)$ - 80 days and $P(C)$ - 64 days;

- between pulses $\mathrm{P}(\mathrm{HC})$ - PCW) - P(HC) intermediate stages from 3 to 5 days are provided to gradually gain the temperature mode of subsurface well construction;

- total duration of one PDHT cycle 156-158 days.

c) Parameters of PDHT(P):

- differ from those of PDHT only by duration of pulse $P(C W)$ with the account of $3-4$ pulses formation, 3 days duration each;

- total duration of one PDHT(P) cycle - up to 168 days.

d) Parameters of CBHT:

- total required volume of heat-carrier having preset characteristics should be equal to $1,2 \mathrm{PV}$ of the pattern treated;

- distribution of the total injected heat carrier volume between the central injection well $(70 \%)$ and peripheral production wells (30\%);

- heat carrier injection into the production well is from 100 to 140 days (in the quantity of $15-25$ thousand tons);

- total number of CBHT cycles for each pattern is 3-

5 , which is exactly determined from the data of patern operation experience.

Calculation of the agent injection mode with PDHT and $\mathrm{PDHT}(\mathrm{P})$ technologies was performed using the results of real formation oil laboratory studies.

The effective temperature for A4 formation, the Gremikhinskoye oil field is equal to $500 \mathrm{C}$ [Fig.3] which is suitable for optimal development of $\mathrm{A4}$ formation. To estimate technological indices of the process the nomogram presented in [Fig.4] was used. The nomogram is plotted as the required total heatcarrier and hot water $Q(t) / Q(x)$ as a function of preset effective iemperature of formation and thermal peculiarities of the injected heat carrier.

The oil production is sucker rod pumping. Thermal methods lechnological efficiency evaluation was done by two procedures specially developed.
The first considers a detailed dynamics of the process development as to putting the injection wells for the agent pumping as well as responded formation zones to injection considering putting the producing wells sinuated within the limits of the zone of response into production.

The . second consideration realizes engineering approach of oil recovery taking into account of thermal stimulation.

Actual data of oil-pool development using thermal technologies and designed indices of similar technologies effectiveness forecast are the basis of this approach.

In both cases rated indices of oil-pool development at natural drive are taken as a basis of comparison.

The major pilot-commercial and commercial development performance of new technologies are given in Table 1. By the beginning of 1994 cumulative oil production from A4 bed of the Gremikhinskoye oil field due to thermal method application existed 2 million tons or $25 \%$ of total oil produced. During 1994 a share of this technology exceeds $40 \%$ of total oil produced. There is no doubt that such a high technological efficiency of thermal stimulation at an early stage of thermal processes development is the result of high efficiency of the new methods (PDHT and PDHT(P)) application.

Low steam-oil and agent-oil ratios, varies within the limits of 3,0-5.0 t/t. point on profitability and high economical efficiency of method applied under the conditions of highly heterogencous porous-fractured reservoir drainage. More than $40 \%$ of total reserves in place are covered by zones of response and formation pressure, close to the initial one $(12,5 \mathrm{MPa})$ is maintained. TCBT technology is now under pilot application at enlarged pilot-commercial section of A4 bed.

Given below are the basic indices of geological characteristics of pilot-commercial pattem:

area $-238,0$ thousands $\mathrm{m}^{2}$.

average effective pay thickness $-35,5 \mathrm{~m}$.

porosity -0.211 .

permeability $-0,105 \mathrm{mkm}^{2}$.

total reserves $-1,3 \mathrm{mln}$.tons.

Current oil rates vary between 3,4 and 9,3 t/day for oil and 14,0-17,0 $\mathrm{v}$ day for liquid.

Total amount of oil recovered is 95,6 thousand tons.

Principle scheme of TCBT technology as applicable for inverted 13-spot pattem bas the following order of carrying out preliminary evaluations and pilot operations: 
- required quantity of heat-carrier is evaluated for the given pilot area considering build $u p$ and maintenance of effective temperature within the boundary of the pattem;

- distribution of the required quantity of heat-carrier for the given pattern is perfomed between central injector and peripheral producing wells;

- rates of agent injection (steam in injection wells) and production wells are sel;

- every cycle of CBHT is composed of three technological stages:

the first stage - simultaneous agent injection through the central steam injection well and three production wells, situated altemately;

- the second stage differs from the first one by changed functions of peripheral producing wells;

- the 3rd stage - agent is injected only through the central steam injection well in PDHT(P) mode.

Cycles are repeated depending on the achieved technological and economic effect in CBHT technologies.

The major performance of the mode is as follows: the required quantity of heat-carrier for the pattern equals to $2.8 \mathrm{mln}$.tons, including injection of 2,0min.tons through steam injection well in PDHT(P) and $0,8 \mathrm{mln}$.tons in production well at the boundary of pattem (every altemating one). Number of cycles comes to 5, rate of agent injection into steam injection well is up to 240.0 vday and into production well - 135,0 - 150,0 t/day, Duration of full cycle of CBHT is 840 days, where stage of heat carrier injection into production well makes 420 days and operation of every production well is 360 days (this stage is corrected by experimental performance). Evaluation of the results for CBHT technology is done up to 2000 year.

Calculations are performed in two options:

Option 1 - a basic one, when the development of the pilot - commercial area is carried out only with injection of agent into the central steam injection well in PDHT(P) mode.

Option2 - when development of the pilot area is carried out with complex application of PDHT(P) and thermal cyclic bed treatment through production wells (CBHT).

As it is evidenced the combined use of PDHT(P) and CBHT technologies as an integral technological process at the pilot - commercial area ensures the increase of current oil recovery factor from 21,0 to $28,4 \%$ by the end of the fourth cycle $(9.2$ years after initiation of the process).

The above technological effect is the result of better sweep of reservoir by thermal process, drawing into development of low permeable "blocks" and enhancing wells productivity.

The technological efficiency will be attained without any additional capital investments. Maximum thermal cyclic efficiency of the process is observed during the first two cycles. Further withdrawal rate indices of the above technologies draw together.

\section{CONCLUSIONS}

New technologies - PDHT. PDHT(P) and CBHT providing high technical and economical futures have been developed, scientifically and experimentally substantiated for stimulation of oil bearing formations with wide range of geological characteristics.

More essential effect can be achieved in conformity with "difficult to recover" reserves.

The major indices of PDHT, PDHT(P) and TCBT technologies can be as follows:

- higher final recovery as compared to the basic technology of oil displacement by thermal slugs;

- reduced capital investment requirements for development of heat treatment process;

- combined application of PDHT(P) and CBHT methods. as an integral technological process, will allow to improve significantly the system of treatment ans at the same time reduce the required number of costly steam injection wells;

- by its physical and technological nature and practical procedure of agent injection and crude production the above technologies do not require additional capital investments. and can be widely used in the world practice with guaranteed technological and economical benefits.

\section{BIBLIOGRAPHY}

1. Patent of the Russian Federation: "Method of development of deposits with high-viscosity oil", $\mathrm{N}$ 1266271 dated 22.06.86. Authors: Kudinov V.I., Kolbikov V.S., Zubov N.V., Datsik M.I., Karasyov S.A.

2. Patent of the Russian Federation: "Method of development of deposits with high-viscosity oil", $\mathrm{N}$ 1365779 dated 08.09.87. Authors: Kudinov V.I. Kolbikov V.S., Zubov N.V., Ivanov V.A., Karasyov S.A.

3. Patent of the Russian Federation: "Method of viscous oil recovery from deposits", N 1744998 dated 01.03.92, Authors: Kolbikov V.S., Zubov N.V., Kudinov V.I., Datsic M.I., Karasyov S.A. 
Gremikhinskoye Oil Field, A4, Udmurtia: Thermal EOR Technologies Application

\begin{tabular}{|c|c|c|c|c|c|c|c|c|c|c|c|c|}
\hline Indices & \multicolumn{10}{|c|}{ Years } & \multicolumn{2}{|c|}{. } \\
\hline+ & 1983 & 1984 & 1985 & 1986 & 1987 & 1988 & 1989 & 1990 & 1991 & 1992 & 1993 & 1994 \\
\hline \multirow{5}{*}{$\begin{array}{l}\text { Total number of wells in } \\
\text { operation } \\
\text { incl. injectors } \\
\text { Anual oil production, thous. t } \\
\text { anual thennal oil produclion, } \\
\text { thous. tons }\end{array}$} & & & & & & & & & & & & \\
\hline & 152 & 251 & 361 & 459 & 561 & 664 & 724 & 738 & $758^{\prime}$ & $789^{\circ}$ & 79 & 760 \\
\hline & 2 & 4 & 7 & 7 & 7 & 36 & 36 & 42 & 43 & 52 & 64 & 76 \\
\hline & 264,1 & 428.7 & 629,0 & 677,4 & 754,5 & 866.3 & 908,2 & 1006,7 & 1027,5 & 1017.6 & 967,8 & 901.5 \\
\hline & - & 6,2 & 25,8 & 45,8 & 92,0 & 176,6 & 228,2 & 249,0 & 290,3 & 311,8 & 353.6 & 374,5 \\
\hline \multirow{4}{*}{$\begin{array}{ll}\text { by leclunologies: } & \text { HWT } \\
& \text { PDHT } \\
& \text { PDHT(P) } \\
& \text { TCBT }\end{array}$} & - & 6.2 & 25,8 & 40,1 & 62,7 & 60,3 & 30,4 & 18,6 & 24,7 & 18,9 & 16,8 & 19,8 \\
\hline & $=$ & $\cdot$ & - & 5,7 & 29,3 & 116,3 & 173,9 & 188,5 & 237.6 & 253,0 & 240.7 & 87.7 \\
\hline & - & . & - & - & - & - & 21,1 & 30,7 & 15.9 & 24,8 & 78,0 & 244,0 \\
\hline & - & - & - & $=$ & - & - & 2,8 & 11,2 & 12,1 & 15,1 & 18,1 & 23,1 \\
\hline \multirow{3}{*}{$\begin{array}{l}\text { Cumulative oil production, } \\
\text { mln. t } \\
\text { cumulative themal oil } \\
\text { production, mln. } 1 \\
\text { Anual liquid production, }\end{array}$} & 0,433 & 0,862 & 1,491 & 2,168 & 2,923 & 3,789 & 4,697 & 5,704 & 6.732 & 7,749 & 8,717 & 9,618 \\
\hline & - & 0,006 & 0,032 & 0,078 & 0,170 & 0,346 & 0,575 & 0,824 & 1,114 & 1,426 & 1,780 & 2,144 \\
\hline & 412,7 & 654.1 & 921.1 & 1016 & 1191 & 1436 & 1636 & 2115 & 2514 & 2783 & 3090 & 3344 \\
\hline Water cut, \% & 38,0 & 34,5 & 31,7 & 33,3 & 36,7 & 39,7 & 44,5 & 52,4 & 59,1 & 63.4 & 68,7 & 73,0 \\
\hline Anual injection, thous. tons & 11,9 & 111,9 & 236,7 & 261,9 & 304.4 & 825,3 & 1279.8 & 1267,6 & 1469.4 & 1262,3 & 1567.0 & 1946,5 \\
\hline heat cantier & 11,9 & 111,9 & 236,7 & 253,8 & 255.4 & 897,0 & 780,1 & 914,5 & 891,7 & $\mathbf{8 8 8 , 0}$ & 1210,0 & 1442,5 \\
\hline cold water & - & - & - & 8,1 & 49,0 & 128,3 & 499,7 & 353,1 & 577,7 & 374,3 & 357,1 & 504,0 \\
\hline Agent-oil ratio, $t / t$ & - & 18,0 & 9,2 & 5.7 & 3,3 & 4.7 & 5,6 & 5,1 & 5,1 & 4,0 & 4,6 & 5,2 \\
\hline Steam-oil ratio, $\mathrm{t} / \mathrm{t}$ & - & 18,0 & 9,2 & 5,5 & 2,8 & 3,9 & 3,4 & 3,7 & 3,1 & 2,8 & 3,5 & 3,8 \\
\hline
\end{tabular}




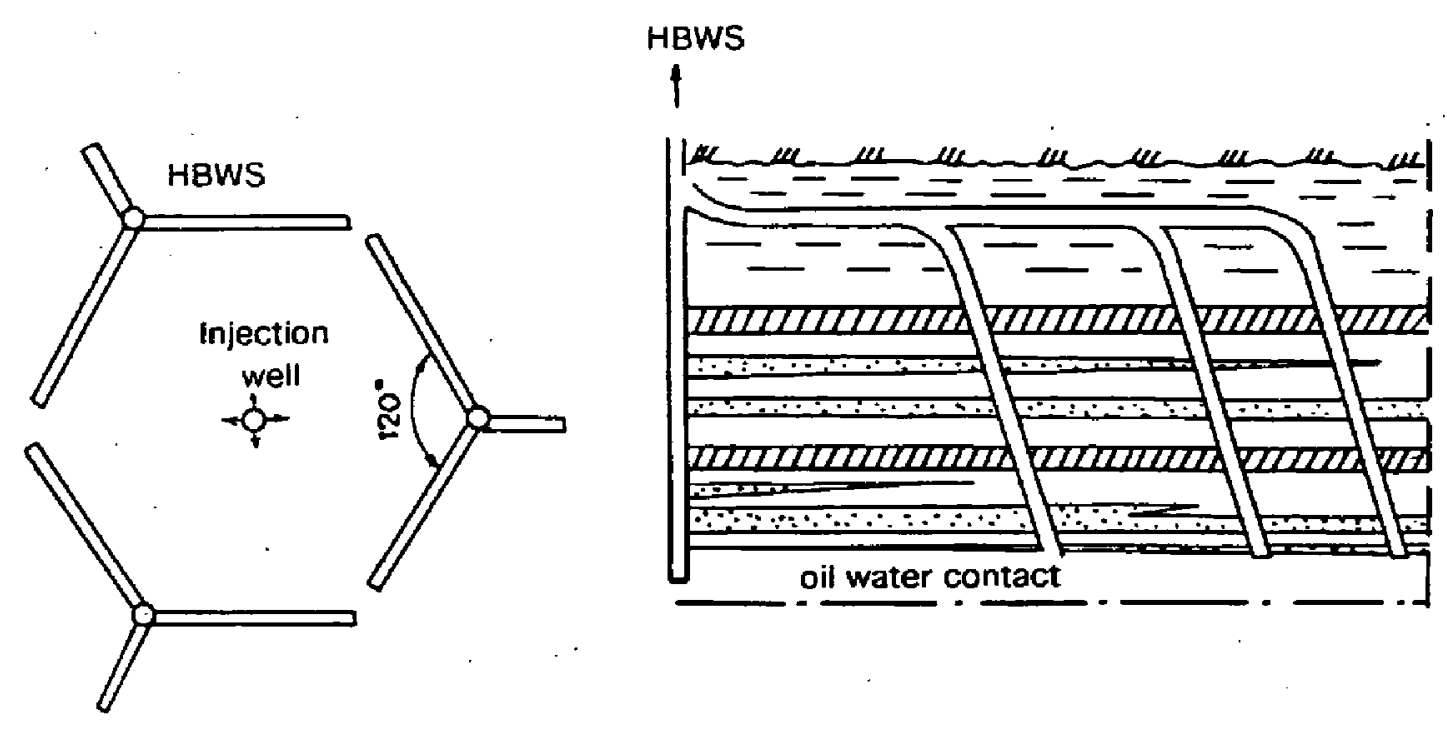

Fig. $i$ The scheme of forming the areal element of heat treatment and drilling - in of the formation by horizontal-branced producing well (option 1)
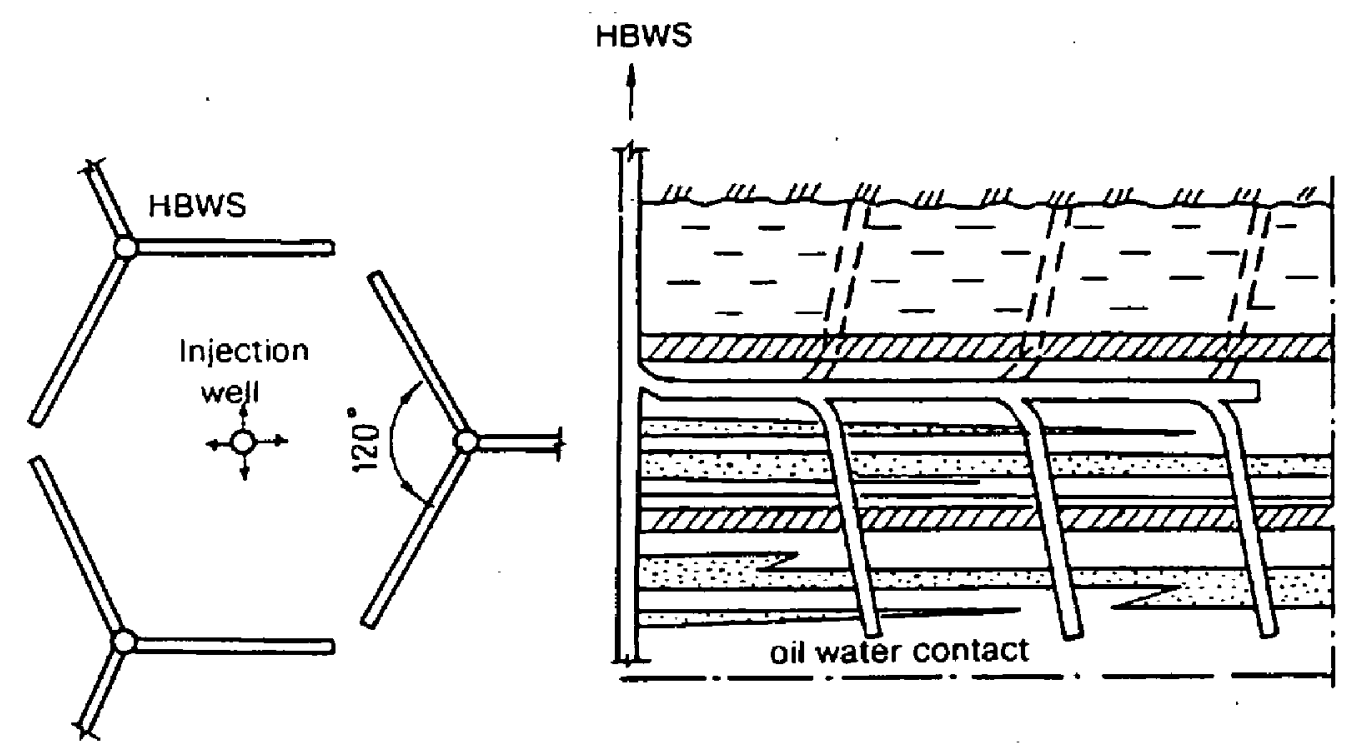

Fig. 2 . The scheme of forming the areal element of heat treatment and drilling - in of the formation by horizontal-branced producing well (option 2) 


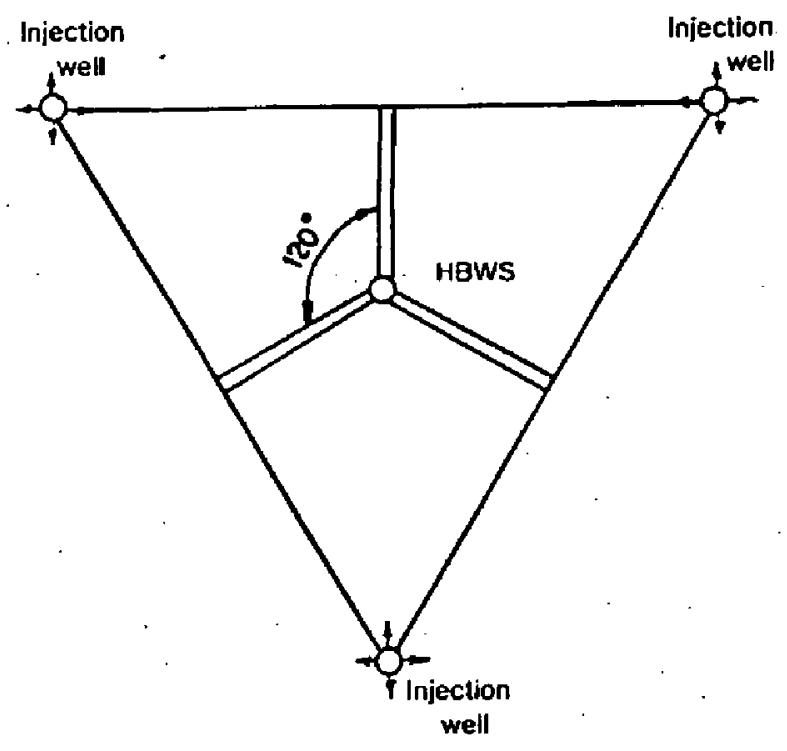

Fig. 3 The scheme of forming the areal element of heat treatment and drilling - in of the formation by horizontal-branced producing well (option 3)

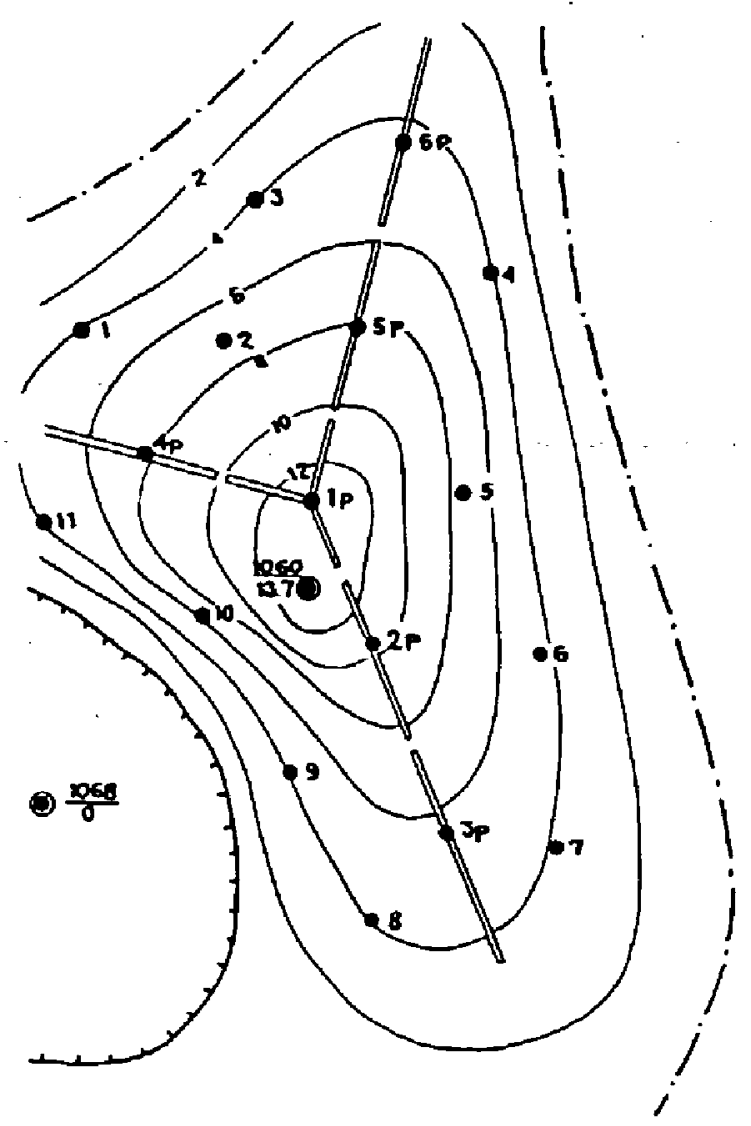

Fig.4 Sharkanskoye oil field: Structure Map, horizontal - branched well $1 p$ - vertical well $2 p, 3 p, \ldots .$. - horizontal - branched producing well 